\title{
Aspects of innate immunity and Parkinson's disease
}

\author{
Yue Huang ${ }^{1,2}$ and Glenda M. Halliday ${ }^{1,2}$ * \\ ' Neuroscience Research Australia, Sydney, NSW, Australia \\ 2 University of New South Wales, Sydney, NSW, Australia
}

\section{Edited by:}

Roger A. Barker, University of Cambridge and Addenbrooke's Hospital, UK

\section{Reviewed by:}

Jason B. Wu, Cedars-Sinai Medical Center, USA

Andreas Hartmann, Assistance Publique des Hopitaux de Paris, Hopital de la Pitie-Salpetriere, France Tamas Revesz, Institute of Neurology, University College London, UK

\section{*Correspondence}

Glenda M. Halliday, Neuroscience Research Australia, Barker Street, Randwick, NSW 2031, Australia. e-mail:g.halliday@neura.edu.au
Genetic studies on PARK genes have identified dysfunction in proteasomal, lysosomal, and mitochondrial enzymes as pathogenic for Parkinson's disease (PD). We review the role of these and similar enzymes in mediating innate immune signaling. In particular, we have identified that a number of PARK gene products as well as other enzymes have roles in innate immune signaling as well as DNA repair and regulation, ubiquitination, mitochondrial functioning, and synaptic trafficking. PD enzymatic dysfunction is likely to contribute to inadequate innate immune responses to a variety of extra- and intra-cellular stimuli, with a number of the innate immunity related enzymes found in the characteristic Lewy body pathology of PD. The decrease in innate immunity in PD is associated with an increase in markers of adaptive immunity, and recent GWAS studies have identified variants in human leukocyte antigen region as associated with late-onset sporadic PD (Hamza et al., 2010; Hill-Burns et al., 2011). Intriguing new data also suggest that peripheral immune responses may be involved, giving some potential to alleviate such peripheral dysfunction more directly in patients with PD. It is now important to identify the cell type specific immune responses contributing to the initial changes that occur in PD, as well as to the propagating immune responses important for the progression of PD pathology between cells and within the brain. Overall, a complex interplay between different types of immunity appear to be involved in the underlying pathology of PD.

Keywords: immunity, mitochondrial dysfunction, Parkinson's disease, synapse dysfunction, ubiquitination

\section{INTRODUCTION}

Although Parkinson's disease (PD) is the most common progressive movement disorder in the elderly, there is still considerable uncertainty about its etiology. Recent advances in genetics have identified a number of PARK genes in families with PD, which have pointed to common underlying intrinsically driven intracellular pathways (Corti et al., 2011). These include dysfunction of the proteosome (McNaught et al., 2001), lysosome (Shin et al., 2005), and mitochondria (Muqit et al., 2006). In particular, leucine repeat rich kinase 2 (LRRK2, PARK8) and PTEN-induced kinase 1 (PINK1, PARK6) are linked to familial dominant and recessive PD respectively. PINK1 deletion causes aberrant expression of genes that regulate innate immune responses (Akundi et al., 2011). LRRK2 expression is enriched in human immune cells and is a target gene of IFN- $\gamma$ (Gardet et al., 2010). Increased LRRK2 expression occurs

\footnotetext{
Abbreviations: CARD, caspase recruitment domain; $\mathrm{CpG}$, polycytosine guanine; ER, endoplasmic reticulum; HDAC, histone deacetylase; IKK, IкB kinase; IRAK, interleukin-1 receptor-associated kinase; JNK, c-Jun N-terminal kinase; LPS, lipopolysaccharides; LRRK2, leucine-rich repeat kinase 2; MAPK, mitogen-activated protein kinase; MAPKK, MAPK kinase; MAVS, mitochondrial antiviral signaling; Mda5, melanoma differentiation-associated gene 5; MPTP, 1-methyl-4-phenyl-1, 2,3,6-tetrahydropyridine; PAMPs, pathogen-associated molecular pattern; PARP, poly (ADP-ribose) polymerase; PD, Parkinson's disease; PINK1, PTEN-induced putative kinase 1; PKR, Protein kinase RNA-activated; RIG-I, RNA helicases protein retinoic acid-inducible gene I protein; TAK1, Transforming growth factor-betaactivated kinase 1; TBK-1, TANK-binding kinase 1; TLR, Toll-like receptor; TRAF6, tumor necrosis factor receptor-associated factor 6 .
}

when an immune response is required (see below). As mutations in these proteins cause $\mathrm{PD}$, this suggests that innate immunity may play a more fundamental role in PD. How these systems interact to cause the fundamental pathology of PD (intracellular Lewy body inclusions made from fibrilized $\alpha$-synuclein protein) to occur within affected neurons needs to be addressed.

Despite considerable organelle dysfunction, neuronal death occurs slowly, initially, and selectively targeting certain brainstem regions with a predisposition for the substantia nigra (Fearnley and Lees, 1991). Neuronal death does not occur in isolation, but is accompanied by considerable neuroinflammation (Orr et al., 2002; Wilms et al., 2003) and intrinsically driven glial cell changes (Halliday and Stevens, 2011). These changes include the accumulation of $\alpha$-synuclein in glia, with many of the PARK gene proteins also concentrating in glia in the human brain (LRRK2, PINK1, DJ-1, parkin; Gandhi et al., 2006; Huang et al., 2008; Halliday and Stevens, 2011; Song et al., 2011). As glia interact most closely with the immune system, we will review how innate immunity is involved in these processes.

The innate immune system is an immediate, non-specific, first line of defense against pathogen invasion, contrasting with the delayed and targeted adaptive immune response (Stone et al., 2009). The specific molecular structure of pathogens (pathogenassociated molecular patterns or PAMPs), like lipopolysaccharides (LPS) or the bacterial DNA motif polycytosine guanine (CpG), are directly recognized by phagocytes, granulocytes, and natural killer cells of the immune system (West et al., 2006). These PAMPs 
bind to Toll-like receptors (TLR) on cells, triggering a cascade of signaling that results in pro-inflammatory cytokine release and complement activation to clear the pathogen or the infected/dead cell through macroautophagy (West et al., 2006).

Pathogens activate cells by binding to specific TLRs through characteristic extracellular multiple leucine-rich repeats domains of TLR (Nguyen et al., 2002). The ultimate induction of interferons and inflammatory cytokines by different pathogens is led by several phosphorylation and subsequent ubiquitination events, with activation of TBK-1 and IKK , JNK and p38 kinase, IKK, MAPK and MAPKK, IRAK, and TAK1 [detailed in previous reviews (Kawai and Akira, 2006; Seth et al., 2006)]. A major pathway is NF-кB activation by its release from I $\mathrm{B}$ allowing its nuclear translocation and the subsequent activation of target genes to occur. I $\mathrm{B}$ release occurs following I $\mathrm{B}$ phosphorylation and consequent degradation through the lysine 48 linked ubiquitin-proteasome system (Silverman and Maniatis, 2001; Wu et al., 2006).

\section{INNATE IMMUNITY AND PD}

Classic PD is not considered an immune disease like multiple sclerosis, and can not be associated with common infectious agents. However, Parkinsonian symptoms can occur after Epstein-Barr virus (EBV) encephalitic infection in patients, with EBV DNA detected in the brain (Espay and Henderson, 2011). This shows that an immune activation in the brain can produce $\mathrm{PD}$-like symptoms, and a number of genetic studies suggest the immune system is commonly involved. Genome-wide association studies (GWAS) show that common variants in human leukocyte antigen (HLA) region are associated with late-onset sporadic PD (Hamza et al., 2010; Hill-Burns et al., 2011). The brains of individuals with PD show upregulation of HLA-DR antigens and the presence of HLA-DR-immunopositive and highly reactive microglia (McGeer et al., 1988). Microglia are the only cells in the substantia nigra that express the initial recognition component of the complement cascade, C1q (Carlsson et al., 2011). Finally, nonsteroidal anti-inflammatory drugs reduce PD risk (Wahner et al., 2007; Steurer, 2011), further supporting some involvement of the immune system in PD.

From a PARK gene perspective, it is of interest that both parkin (PARK2) and LRRK2 (PARK8) are genes associated with leprosy (Cardoso et al., 2011), which is a chronic infectious disease of peripheral nerves. LRRK2 is also a risk gene for inflammatory bowel disease (Van Limbergen et al., 2009; Torkvist et al., 2010; Umeno et al., 2011), and there is much discussion about PD being initiated from peripheral neurons within the gut (enteric nervous system; Braak et al., 2003). In an animal model of ulcerative colitis, there is an alteration of the blood-brain-barrier (BBB) permeability that leads to more substantive cell loss to pathogen-induced cell loss of the substantia nigra (Villaran et al., 2010). Interestingly, treatment of the ulcerative colitis ameliorated cell loss in the brain in this model (Villaran et al., 2010). This could suggest a more direct link between immune defense mechanisms in peripheral neurons and the later onset of PD. Deletions within PINK1 (PARK6) or DJ-1 (PARK7) genes cause aberrant expression of genes involved in the p38 MAP kinase/NF- $\kappa$ B signaling pathway causing changes in the regulation of the innate immune response (Cornejo Castro et al., 2010; Akundi et al., 2011). This suggests that many PARK genes also have significant influence on the immune system which may be important for the onset and/or progression of PD.

A number of animal models of the neuronal loss in PD use direct initiation of the innate immune system to model this aspect of PD. Administration of LPS induces dramatic cell loss in primary neuronal cultures and direct injection of LPS into the substantia nigra produces progressive nigrostriatal degeneration and movement abnormalities in animal models of PD (Liu, 2006; Dutta et al., 2008). These LPS PD models trigger TLR4 mediated signaling pathways (Carvey et al., 2003; Visintin et al., 2003). Even intraperitoneal and in utero injections of LPS cause degeneration of the nigrostriatal system (Ling et al., 2002; Perry, 2004), consistent with peripheral effects causing PD-like neurodegeneration. These innate immunity models of PD cause neurodegeneration and microglial activation in a time and LPS dose dependent manner (Liu, 2006; Dutta et al., 2008). Similar direct injections of TLR3 into the substantia nigra produce nigrostriatal degeneration (Deleidi et al., 2010). These studies show that strong stimulators of the innate immune system and increased numbers of innate immune receptors can produce significant site-specific neurodegeneration, perhaps suggesting that the nigrostriatal system is particularly vulnerable to immune activation.

Innate immune signaling also plays a role in the abnormal deposition of $\alpha$-synuclein. In $\alpha$-synuclein overexpressing models, ablation of TLR 4 augments the deposition of $\alpha$-synculein due to disruption of the ability of microglia to adequately phagocytose $\alpha$-synuclein (Stefanova et al., 2011). This suggests that certain aspects of innate immunity are required for initial protection from excessive extracellular $\alpha$-synuclein. Whether these mechanisms play a role in patients is more difficult to determine. Overall, these studies suggest that the innate immune system can play both neuroprotective and neurotoxic roles depending on the circumstances.

\section{ADAPTIVE IMMUNITY AND PD}

In contrast to the "non-specific" innate immune system, the adaptive immune response is cell mediated and highly specialized to remove a specific antigen. It is mainly composed of two parts: humoral immunity, which is mediated by B-lymphocytes, and cell mediated immunity, which is mediated by T-lymphocytes. The CNS was traditionally considered as an "immune privileged" site due to its protection by the $\mathrm{BBB}$, which prevents toxins and infections from reaching the CNS. However, in PD the BBB is disrupted due to activated microglia and monocytes in PD brain (Stone et al., 2009). IgG, but not IgM, has been shown bound to dopamine neurons in the substantia nigra of idiopathic and familial PD patients, but not in age-matched controls (Orr et al., 2005). In addition, LRRK2, a causative gene for PD (see above), regulates B2-lymphocyte function (Kubo et al., 2010). This suggests that adaptive immunity may also be involved in the progression of PD (Figure 1).

Apart from B-lymphocyte involvement in $\mathrm{PD}$, both $\mathrm{CD} 4^{+}$and $\mathrm{CD}^{+}$T-lymphocytes have been found in the SN of PD patients, and $\mathrm{CD} 4{ }^{+} \mathrm{T}$-lymphocytes are responsible for the T-cell-mediated immunopathology (Brochard et al., 2009). The expression of CD95 ligand (Fas) has been shown to be important for the capacity 


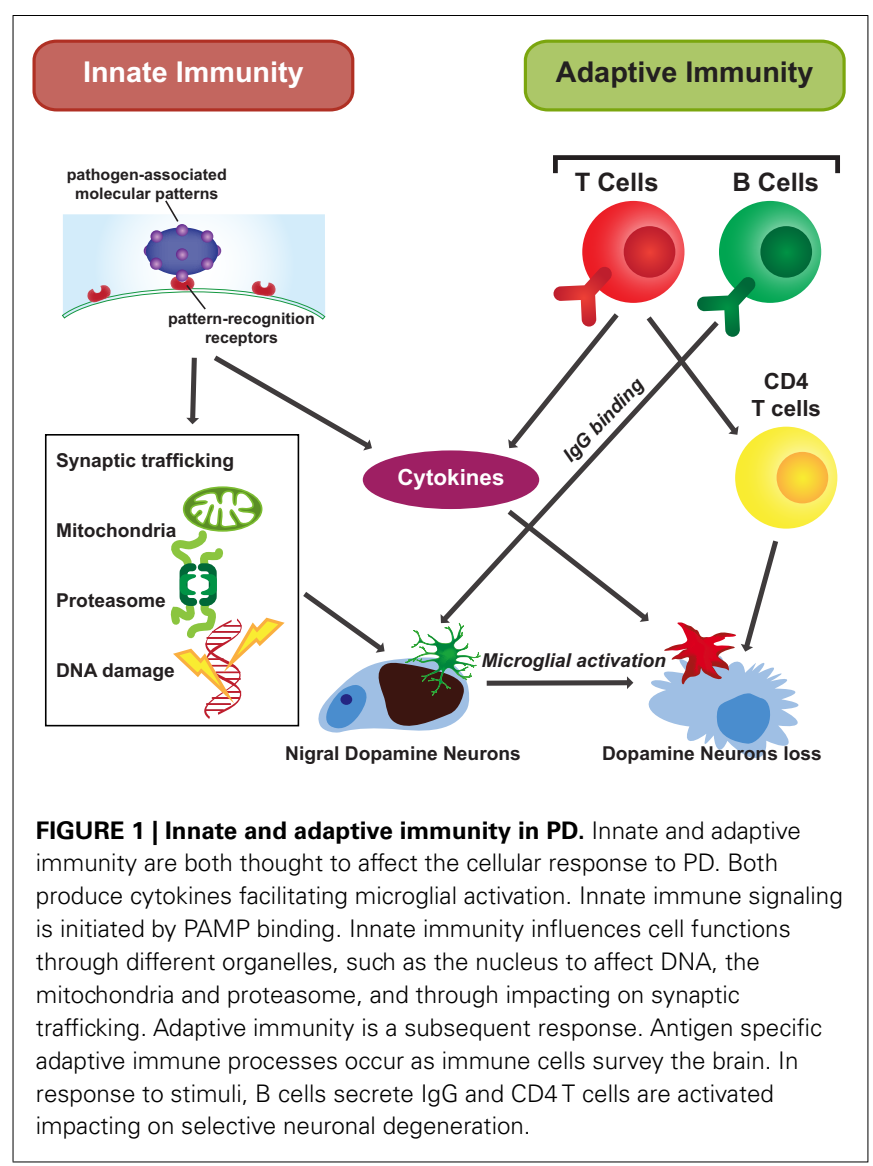

of T-lymphocytes to induce neuronal death (Brochard et al., 2009). T-lymphocyte cells and T cell receptor (TCR) associated CD3, a polypeptide complex comprised of four distinct chains (CD3 $\gamma$, $\mathrm{CD} 3 \delta, \mathrm{CD} 3 \varepsilon$, and $\mathrm{CD} 3 \zeta$ ), are found in the PD characteristic Lewy body lesions (Castellani et al., 2011), providing another direct link between cell mediated immunity and PD pathology (Figure 1).

Through activation of both the adaptive and innate immune systems, cytokines are induced and secreted. Circulating IL-12 and IL-10 are significantly elevated in PD patients compared with controls (Rentzos et al., 2009) and our data show that the protein levels of IL-10 and GM-CSF are elevated in the cortex of patients with PD (unpublished data). Intercellular adhesion molecule-1 (ICAM-1)-positive glia are increased in the substantia nigra of PD brains (Miklossy et al., 2006). Further analysis of these immune responses in the brains of patients with PD may provide more specific cytokine targets for modifying detrimental immune responses in $\mathrm{PD}$.

\section{INNATE IMMUNITY AND DNA REPAIR AND REGULATION IN PD}

The presence of genomic DNA single and double-strand breaks is very common in PD affected brain regions (Hegde et al., 2006). At early stages of DNA damage, DNA sensing molecules (such as PARP and ATM) activate and cause a signaling cascade for repair (Herceg and Wang, 2001). Histone deacetylases (HDAC) are important suppressors of gene transcription, but also deacetylates the p62 subunit of NF- $\kappa \mathrm{B}$ increasing its binding to
IкB and suppressing innate immunity and interferon-stimulated transcription (Babic et al., 2004; Into et al., 2010). HDACs have been localized to Lewy bodies in patients with PD (TakahashiFujigasaki and Fujigasaki, 2006), indicating that they are involved in $\mathrm{PD}$ pathogenesis. Inhibiting HDAC alleviates dopamine depletion in models of PD (Outeiro et al., 2007) and is protective by enhancing $\alpha$-synuclein expression in neurons (Nusinzon and Horvath, 2003; Leng and Chuang, 2006), possibly in concert with an increased innate immune response.

Poly (ADP-ribose) polymerase catalyzes the attachment of ADP ribose units from NAD to nuclear proteins after DNA damage, resulting in three major outcomes, DNA repair, activation of transcription factors (notably NF- $\kappa$ B), and/or cell death due to NAD depletion and release of apoptosis releasing factor from mitochondria (Kauppinen and Swanson, 2007). PARP negatively regulates $\alpha$-synuclein expression by binding to the $\alpha$-synuclein promoter Rep1 region (Chiba-Falek et al., 2005) and $\alpha$-synuclein protein suppresses PARP activity (Adamczyk and Kazmierczak, 2009). Inhibition of PARP activation protects mice from MPTP-induced parkinsonism (Mandir et al., 1999; Leng and Chuang, 2006). PARP may protect against PD through increasing innate immune signaling.

ATM is a kinase that is recruited to phosphorylate histones for DNA repair, signaling molecules for cell cycle arrest or apoptosis, and nuclear IKK $\gamma$ (NF- $\kappa \mathrm{B}$ essential modulator; Habraken and Piette, 2006; Hinz et al., 2010; Hadian and Krappmann, 2011). Phosphorylation of IKK $\gamma$ leads to its ubiquitination and cytoplasmic translocation where it associates with the rest of the IKK complex, resulting in IKK activation followed by subsequent NF- $\kappa \mathrm{B}$ activation and inflammatory cytokines production (Chen, 2005). ATM has also recently been shown to regulate proteasomemediated protein turnover through suppression of the ISG15 pathway (Wood et al., 2011). ISG15 is an interferon-stimulated gene activated by viral infection and important in antiviral defense and innate immunity (Skaug and Chen, 2010). It is a ubiquitin-like protein that can be attached to both host and viral proteins (Skaug and Chen, 2010). ATM-deficient mice exhibit a selective loss of dopamine nigrostriatal neurons (Eilam et al., 1998), implicating dysfunction of ubiquitination as a factor in PD neurodegeneration, and specifically of ubiquitination in the innate immune system.

\section{INNATE IMMUNITY AND UBIQUITINATION IN PD}

The expression of ISG15 is increased in Crohn's disease (Labbe et al., 2011), an inflammatory bowel disorder sharing common genetic and environmental risk factors with PD (Bihari and Lees, 1987; Bialecka et al., 2007). Both ISG15 and LRRK2 (PARK8) are targets of interferon regulation (Figure 2). Interferon also regulates proteasome processing of ubiquitinated protein degradation into small peptides (Rivett et al., 2001; Piccinini et al., 2003; Figure 2). Ubiquitin is a small molecule and through lysine 48 and lysine 63 forms polyubiquitin chains for protein degradation and cellular localization (Ikeda and Dikic, 2008).

Among PARK genes, parkin has a variety of functions. It not only promotes lysine 48 linked ubiquitination for substrate degradation via the proteasome, but also functions in lysine 63 ubiquitin chain assembly to regulate diverse cellular processes, such as ribosome control, protein sorting and trafficking, and endocytosis of 


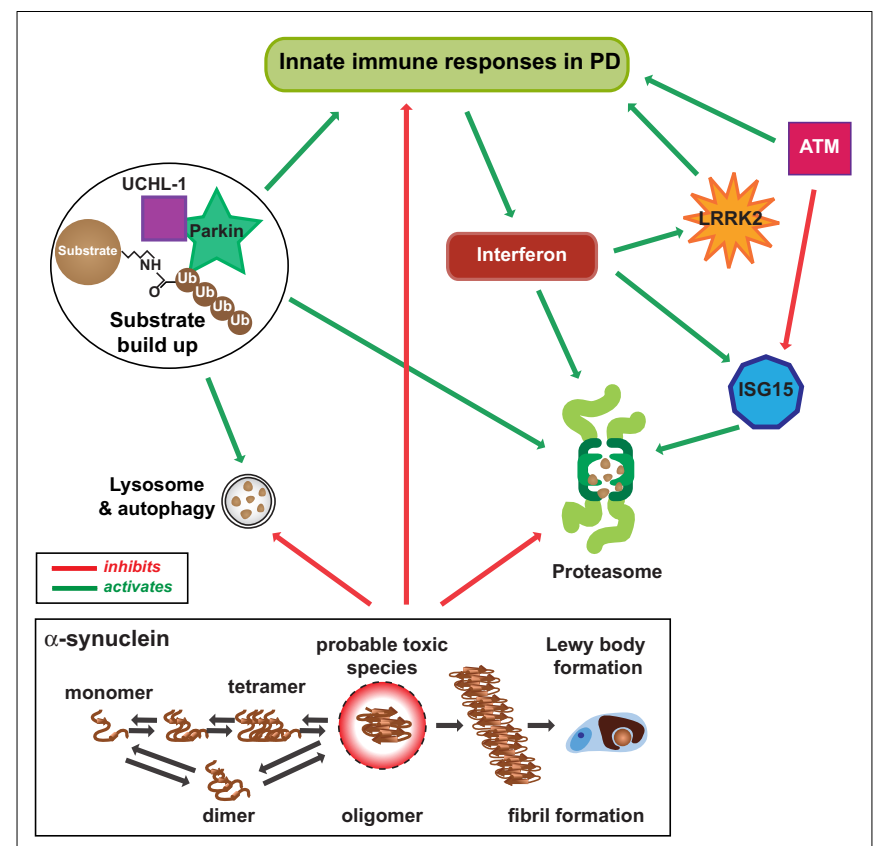

FIGURE 2 | Innate immunity and the ubiquitin-proteasome system in PD. Innate immunity is used by the cell to increase proteasome degradation of unwanted proteins by direct and indirect stimulation of the protesome through interferon- $\gamma$ and ISG15, a ubiquitin-like protein that can be attached to both host and viral proteins. ATM (and appropriately functioning LRRK2) usually stimulates innate immune signaling when necessary. However, ATM also regulates proteasome-mediated protein turnover through suppression of the ISG15 pathway, and together with dysfunctional LRRK2 could decrease proteasome activity necessary for an adequate immune response and the degradation of normal cellular protein substrates, like dimer or tetramer forms of $\alpha$-synuclein. As these forms are normally degraded through the ubiquitin/proteasome and lysosome/autophagy pathways, along with other cellular substrates, dysfunction in these pathways would increase $\alpha$-synuclein to form toxic oligomeric species that also inhibit the proteasome and autophagy pathways, as well as innate immunity. This scenario would lead to the increase in toxic oligomers of $\alpha$-synuclein that aggregate into fibrils to form Lewy bodies over time.

membrane proteins (Doss-Pepe et al., 2005). Lysine 63 linked ubiquitin chains promote the degradation of membrane proteins by the lysosome (Doss-Pepe et al., 2005). It is notable that $\alpha$-synuclein is degraded via both the proteasome and lysosome pathways (Shin et al., 2005), suggestive that lysine 48 and lysine 63 linked ubiquitin chains are both important in the pathogenesis of PD (Figure 2). UCH-L1 has two opposing enzymatic activities, deubiquitination and ubiquityl ligase. The UCH-L1 ligase activity forms lysine 63 linked polyubiquitin chains (Liu et al., 2002). Lysine 63 multiubiquitin chains are also stimulated by $\alpha$-synuclein (Doss-Pepe et al., $2005)$, and $\alpha$-synuclein filaments and oligomers or its mutants inhibit proteasome function (Tanaka et al., 2001; Lindersson et al., 2004). These three genetically linked PD proteins all contribute to lysine 63 multiubiquitin chain formation. Dysfunction of this system is likely to decrease innate immune responses in PD.

Both lysine 48 and lysine 63 linked ubiquitin chains are known to be involved in anti-pathogen signaling cascades. In particular, lysine 63 linked ubiquitination is essential for NF- $\kappa \mathrm{B}$ activation (detailed in review of Wu et al., 2006). Phosphorylation of IкB that releases NF- $\kappa \mathrm{B}$ only occurs when the kinase IKK $\beta$ is released from its complex following IKK $\gamma$ phosphorylation and lysine 63 linked degradation. Some other key immune response signaling molecules, such as TRAF6, also function as the lysine 63 linked ubiquitin E3 ligase to activate kinase activity (Kawai and Akira, 2006), and TRAF5 has been identified as a downstream target of VISA (see below) that mediates both IRF-3 and NF- $\kappa \mathrm{B}$ activation (Tang and Wang, 2010).

\section{INNATE IMMUNITY AND MITOCHONDRIAL FUNCTION IN PD}

The proper functioning of mitochondria is crucial for adequate innate immune defense (Qi et al., 2007; Tang and Wang, 2010; West et al., 2011). Intracellular double-stranded RNA originating from viruses or virus replication is recognized by RIG-I and Mda5, which contain a caspase recruitment domain (CARD; Figure 3). Activated RIG-I/Mda5 passes the signal to mitochondrial antiviral signaling (MAVS/VISA) proteins via a CARD-CARD domain interaction (Figure 3). The C-terminal of MAVS/VISA bind to mitochondria to activate NF- $\kappa \mathrm{B}$ and start interferon $\alpha$ and $\beta$ production (Qi et al., 2007; Figure 3). Upon viral infection, MAVS/VISA immigrate from the outer membrane into the mitochondrial detergent-resistant membrane fraction, suggesting that mitochondria react and contribute to antiviral signaling (Qi et al., 2007; Figure 3). In addition to regulating antiviral signaling, there is mounting evidence that mitochondria facilitate antibacterial immunity by generating reactive oxygen species and contributing to innate immune activation following cellular damage and stress (Nakahira et al., 2011).

Most nuclear encoded PARK gene products are located within mitochondria (Table 1), such as PINK1, DJ-1, Omi/HtrA2, and LRRK2, suggesting mitochondrial dysfunction is common in PD. The mitochondrial complex I has been shown to be selectively reduced in PD vulnerable regions, such as the substantia nigra (Schapira et al., 1989). The mitochondrial complex I inhibitor rotenone and mitochondrial toxin MPTP (1-methyl 4-phenyl 1,2,3,6-tetrahydropyridine) induce selective dopamine neuron loss and a parkinsonian syndrome and have been used as a major model for studying the tissue aspects of PD (Langston and Ballard, 1984; Betarbet et al., 2000). These changes may decrease the cellular responses of the innate immune system in PD.

\section{INNATE IMMUNITY AND SYNAPTIC TRAFFICKING IN PD}

Most enveloped animal RNA and DNA viruses enter host cells via receptor-medicated endocytosis or viral membrane fusion with the plasma membrane in order to replicate. Endocytosis impinges on viral infection at a number of different cellular levels, from the plasma membrane to endosome to lysosome or alternatively to Golgi, and to ER (Figure 4; Hacker et al., 1998; Leadbetter et al., 2002; Diebold et al., 2004). Viral proteins accumulate in the ER during viral replication and elicit ER stress. Viral replication induced ER stress disturbs vesicle trafficking within the intracellular membranous web (Goodridge et al., 2011).

Many PARK genes are associated with endocytosis and synaptic vesicle trafficking. $\alpha$-Synuclein, parkin and UCH-L1 concentrate in the presynapse and associate with synaptic vesicles, anchoring and regulating the undocked pool of presynaptic vesicles (Di Rosa et al., 2003; Ferrer, 2009). $\alpha$-Synuclein acts as a molecular 


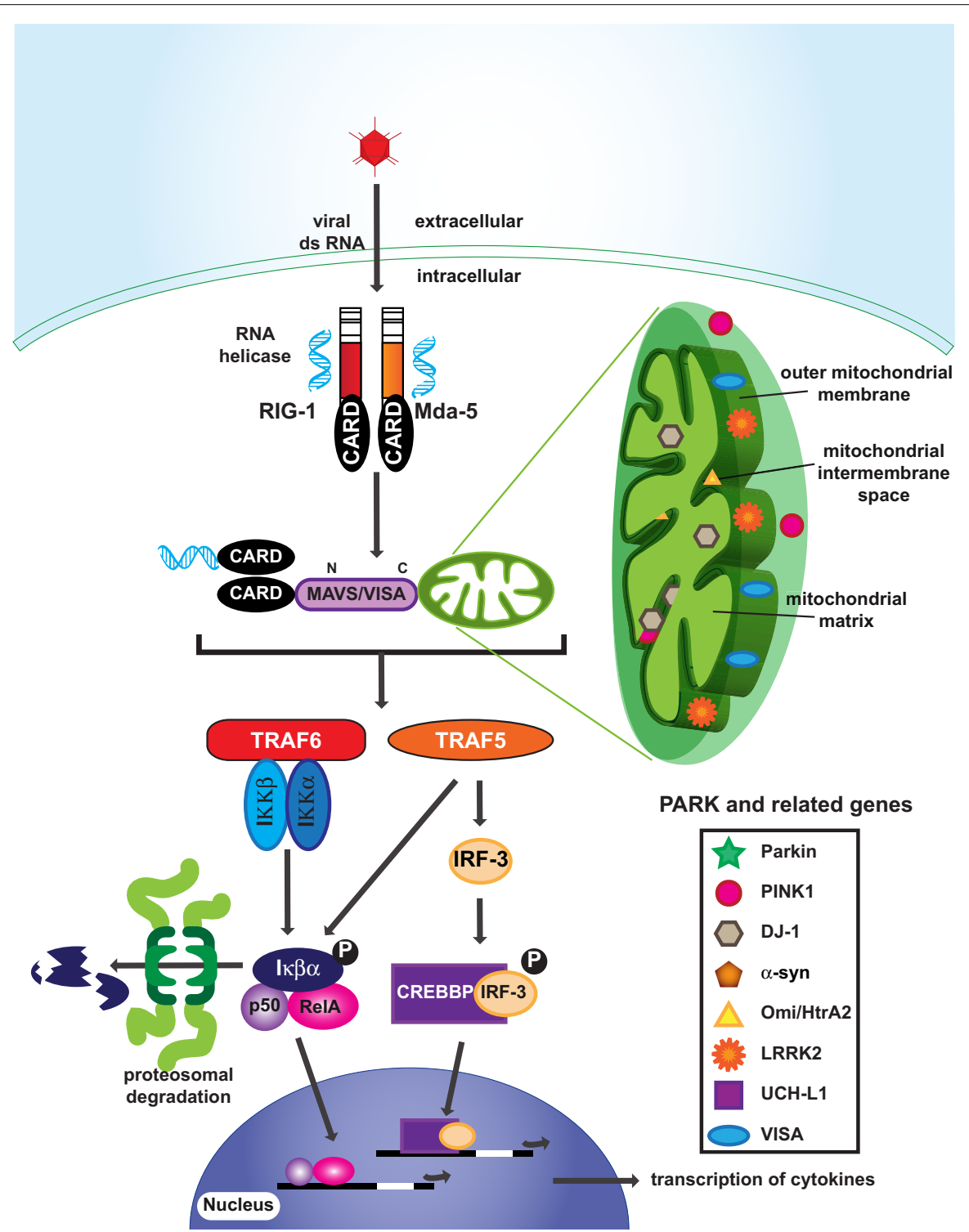

FIGURE 3 | Innate immunity and mitochondria in PD. Many PARK related gene products are located in mitochondria, implicating mitochondrial

membrane of mitochondria are involved in viral infection signaling by dysfunction in PD. Interestingly, MAVSNISA that are attached to the outer activating TRAF6 and TRAF5. Phosphorylation of $І_{\kappa} \beta \alpha$ and IRF-3 leads to nuclear translocation of transcription factors and the production of cytokines.

Table 1 | Cellular localization and functions PARK and related genes

\begin{tabular}{llll}
\hline & $\begin{array}{l}\text { Cellular location indicative functions in mitochondria } \\
\text { and synaptic trafficking }\end{array}$ & Ubiquitination & Reference \\
\hline Parkin & $\begin{array}{l}\text { Outer mitochondrial membrane Synaptic vesicles and the } \\
\text { synaptic membrane }\end{array}$ & Lysine 48-, 63-linked ubiquitin E3 ligase & Kubo et al. (2001); Darios et al. (2003) \\
DJ-1 & Mitochondrial matrix and inter-membrane space & NA & Zhang et al., 2005) \\
PINK1 & Mitochondria & Upstream of parkin & Valente et al. (2004) \\
Omi/HtrA2 & Mitochondrial inter-membrane space & NA & Strauss et al. (2005) \\
LRRK2 & Outer mitochondrial membrane & NA & West et al. (2005) \\
a-synuclein & Presynaptic terminal & Promote 63 linked ubiquitin assemble & Iwai et al. (1995) \\
UCH-L1 & Synaptic vesicle & Lysine 63 linked ubiquitin E3 ligase & Liu et al. (2002) \\
VISA & Outer mitochondrial membrane & NA & Seth et al. (2005) \\
\hline
\end{tabular}




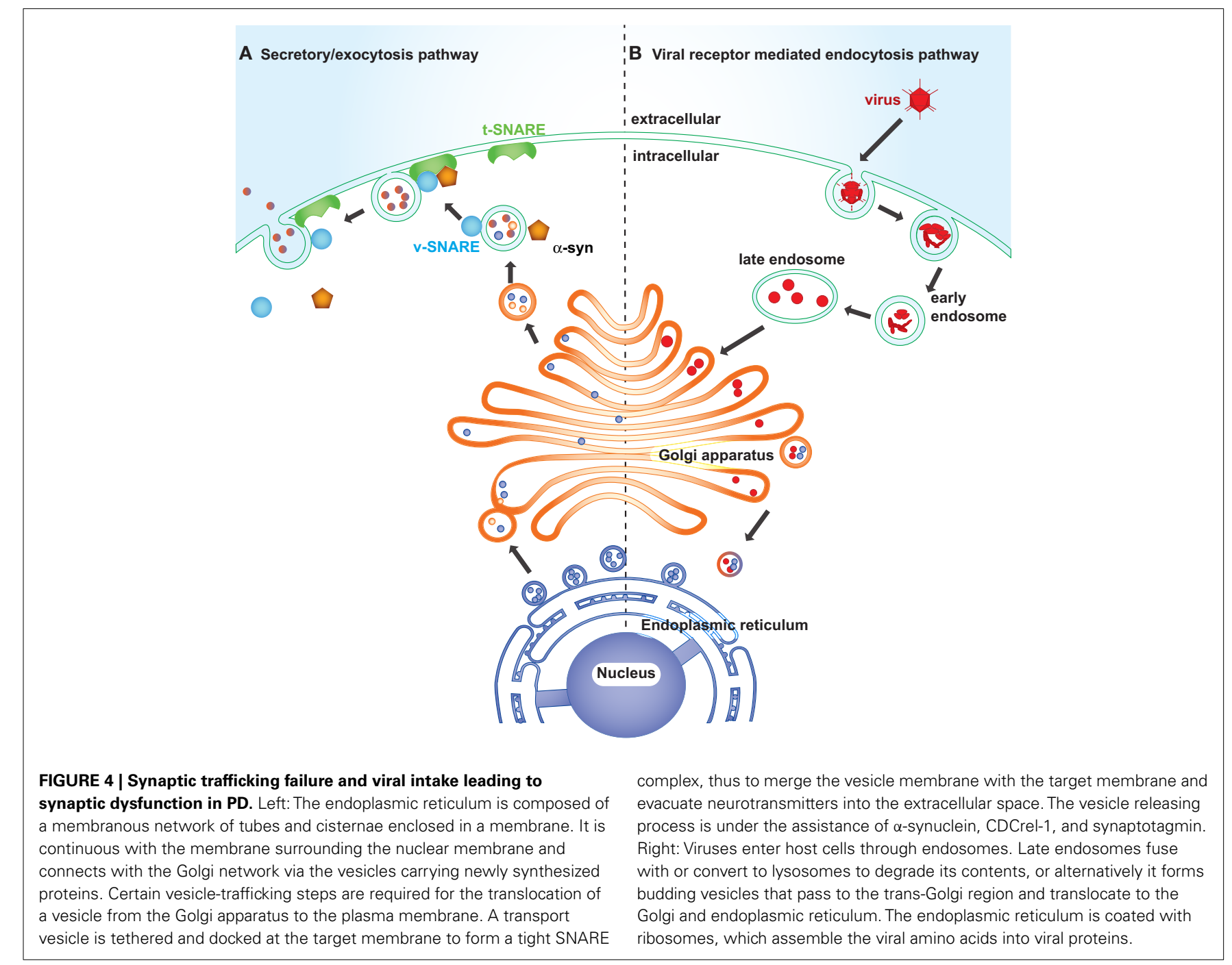

chaperone, assisting in the folding and refolding of synaptic proteins called SNAREs, which are crucial for the release of neurotransmitters at the neuronal synapse, vesicle recycling, and synaptic integrity (Chandra et al., 2005). Upon the arrival of action potentials at the synaptic terminal, SNARE complexes, assembly of vesicle membrane (v-SNARE) and the presynaptic plasma membrane (t-SNARE), fuse the vesicle at the plasma membrane to release neurotransmitter into the synaptic cleft (Chandra et al., 2005; Fortin et al., 2005). Parkin ubiquitinates and regulates the turnover of the synaptic vesicle-associated protein, CDCrel-1, a synaptic vesicle-enriched septin GTPase implicated in the inhibition of exocytosis through its interactions with the SNARE complex component, syntaxin (Zhang et al., 2000). Another substrate of parkin is synaptotagmin XI, a member of the synaptotagmin family that is well characterized in vesicle formation and docking by interaction with SNAREs (Huynh et al., 2003). Loss of function of $\alpha$-synuclein, parkin, or DJ-1 reduces neurotransmission and synaptic vesicle trafficking (Abeliovich et al., 2000; Goldberg et al., 2005). UCH-L1 deficient mice also show altered vesicle transport gene expression (Bonin et al., 2004). Reduced innate immunity allowing for pathogen replication would significantly exacerbate any loss of synaptic function caused by PARK gene products (Figure 4) precipitating frank degeneration.

\section{CONCLUSION}

A number of intrinsically driven cellular pathways shown to be dysfunctional in PD are important in mediating innate immune signaling. These important intracellular pathways have been identified through genetic studies in patients with PD. More recent genetic studies have also implicated immune pathways in the pathogenesis of PD. In particular, we have identified a number of PARK gene products as well as other enzymes that have dual roles in innate immune signaling as well as proteasome, lysosome, and mitochondrial functioning. The additional enzymes identified are important for DNA repair and regulation, ubiquitination, mitochondrial function, and synaptic trafficking. These pathways appear to lose their ability to mount an adequate innate immune response to PD and experimental manipulation of many of these intracellular molecules has been associated with characteristic PD pathologies in animal models. Intriguing new data also 
suggest that peripheral immune responses may be involved, with the potential to alleviate such peripheral dysfunction more directly in patients with PD.

Most important, the molecular pathways involved are likely to function in a cell type specific manner (Ledesma et al., 2002), a concept that has not yet been evaluated substantially in patients with PD. The cross-talk between neurons and glia is crucial for an adequate immune response, with astrocytes considered particularly important (Halliday and Stevens, 2011; Schmidt et al., 2011). Astrocytic endfeet form part of the BBB and may serve as ideal sentinel cells able to sense the appearance of toxins and viral pathogens (Scumpia et al., 2005), similar to their cousins found in the gut (Savidge et al., 2007; Daneman and Rescigno, 2009). Astroglia in both the brain and gut regulate barrier function and membrane permeability (Savidge et al., 2007; Daneman and Rescigno, 2009), functions which may be important for the cell to cell transfer of $\alpha$-synuclein

\section{REFERENCES}

Abeliovich, A., Schmitz, Y., Farinas, I., Choi-Lundberg, D., Ho, W. H., Castillo, P. E., Shinsky, N., Verdugo, J. M., Armanini, M., Ryan, A., Hynes, M., Phillips, H., Sulzer, D., and Rosenthal, A. (2000). Mice lacking alpha-synuclein display functional deficits in the nigrostriatal dopamine system. Neuron 25, 239-252.

Adamczyk, A., and Kazmierczak, A. (2009). Alpha-synuclein inhibits poly (ADP-ribose) polymerase-1 (PARP-1) activity via NO-dependent pathway. Folia Neuropathol. 47, 247-251.

Akundi, R. S., Huang, Z., Eason, J., Pandya, J. D., Zhi, L., Cass, W. A., Sullivan, P. G., and Bueler, H. (2011). Increased mitochondrial calcium sensitivity and abnormal expression of innate immunity genes precede dopaminergic defects in Pink1-deficient mice. PLoS ONE 6, e16038. doi:10.1371/journal.pone. 0016038

Babic, I., Jakymiw, A., and Fujita, D. J. (2004). The RNA binding protein Sam68 is acetylated in tumor cell lines, and its acetylation correlates with enhanced RNA binding activity. Oncogene 23, 3781-3789.

Betarbet, R., Sherer, T. B., Mackenzie, G., Garcia-Osuna, M., Panov, A. V., and Greenamyre, J. T. (2000). Chronic systemic pesticide exposure reproduces features of Parkinson's disease. Nat. Neurosci. 3, 1301-1306.

Bialecka, M., Kurzawski, M., Klodowska-Duda, G., Opala, G., Juzwiak, S., Kurzawski, G., Tan, E. K., and Drozdzik, M. (2007). CARD15 variants in patients with sporadic Parkinson's disease. Neurosci. Res. 57, 473-476.
Bihari, K., and Lees, A. J. (1987). Cigarette smoking, Parkinson's disease and ulcerative colitis. J. Neurol. Neurosurg. Psychiatr. 50, 635.

Bonin, M., Poths, S., Osaka, H., Wang, Y. L., Wada, K., and Riess, O. (2004). Microarray expression analysis of gad mice implicates involvement of Parkinson's disease associated UCHL1 in multiple metabolic pathways. Brain Res. Mol. Brain Res. 126, 88-97.

Braak, H., Rub, U., Gai, W. P., and Del Tredici, K. (2003). Idiopathic Parkinson's disease: possible routes by which vulnerable neuronal types may be subject to neuroinvasion by an unknown pathogen. J. Neural Transm. 110, 517-536.

Brochard, V., Combadiere, B., Prigent, A., Laouar, Y., Perrin, A., BerayBerthat, V., Bonduelle, O., AlvarezFischer, D., Callebert, J., Launay, J. M., Duyckaerts, C., Flavell, R. A., Hirsch, E. C., and Hunot, S. (2009). Infiltration of CD4+ lymphocytes into the brain contributes to neurodegeneration in a mouse model of Parkinson disease. J. Clin. Invest. 119, 182-192.

Cardoso, C. C., Pereira, A. C., De Sales Marques, C., and Moraes, M. O. (2011). Leprosy susceptibility: genetic variations regulate innate and adaptive immunity, and disease outcome. Future Microbiol. 6, 533-549. M., Depboylu, C., Arias-Carrion, O., Schnurrbusch, S., Rosler, T. W., Wozny, W., Schwall, G. P., Groebe, K., Oertel, W. H., Brundin, P., Schrattenholz, A., and Hoglinger, G. U. (2011). Systemic administration of neuregulin-1betal protects dopaminergic neurons in a mouse model of Parkinson's disease. J. Neurochem. 117, 1066-1074.
Carlsson, T., Schindler, F. R., Hollerhage,

pathology as well as more traditional infectious agents. The increased expression of PARK gene proteins in astrocytes (see above) and their lack of activation to PD pathology in patients (Mirza et al., 2000; Halliday and Stevens, 2011) lends weight to a loss of innate immunity and BBB function in PD that potentially increases membrane and cellular permeability leading to increased toxin and pathogen infiltration in the brain. In addition to the direct cellular damage to vulnerable neurons this would initiate, pathogen exposure may also activate the alternate adaptive immune responses that are thought to participate in propagating the pathology of PD.

\section{ACKNOWLEDGMENTS}

We wish to thank Heidi Cartwight for the figurework. Yue Huang is funded by a University of New South Wales Goldstar award. Glenda M. Halliday is funded as a Senior Principal Research Fellow of the National Health and Medical Research Council of Australia.

Carvey, P. M., Chang, Q., Lipton, J. W., and Ling, Z. (2003). Prenatal exposure to the bacteriotoxin lipopolysaccharide leads to longterm losses of dopamine neurons in offspring: a potential, new model of Parkinson's disease. Front. Biosci. 8 s826-s837.

Castellani, R. J., Nugent, S. L., Morrison, A. L., Zhu, X., Lee, H. G., Harris, P. L., Bajic, V., Sharma, H. S., Chen, S. G., Oettgen, P., Perry, G., and Smith, M. A. (2011) CD3 in Lewy pathology: does the abnormal recall of neurodevelopmental processes underlie Parkinson's disease. J. Neural Transm. 118, 23-26.

Chandra, S., Gallardo, G., FernandezChacon, R., Schluter, O. M., and Sudhof, T. C. (2005). Alphasynuclein cooperates with CSPalpha in preventing neurodegeneration. Cell 123, 383-396.

Chen, Z. J. (2005). Ubiquitin signalling in the NF-kappaB pathway. Nat. Cell Biol. 7, 758-765.

Chiba-Falek, O., Kowalak, J. A., Smulson, M. E., and Nussbaum, R. L. (2005). Regulation of alphasynuclein expression by poly (ADP ribose) polymerase-1 (PARP-1) binding to the NACP-Rep1 polymorphic site upstream of the SNCA gene. Am. J. Hum. Genet. 76 , 478-492.

Cornejo Castro, E. M., Waak, J., Weber, S. S., Fiesel, F. C., Oberhettinger, P., Schutz, M., Autenrieth, I. B., Springer, W., and Kahle, P. J. (2010). Parkinson's diseaseassociated DJ-1 modulates innate immunity signaling in Caenorhabditis elegans. J. Neural Transm. 117, 599-604.

Corti, O., Lesage, S., and Brice, A. (2011). What genetics tells us about the causes and mechanisms of Parkinson's disease. Physiol. Rev. 91, 1161-1218.

Daneman, R., and Rescigno, M. (2009). The gut immune barrier and the blood-brain barrier: are they so different? Immunity 31 , 722-735.

Darios, F., Corti, O., Lucking, C. B., Hampe, C., Muriel, M. P., Abbas, N., Gu, W. J., Hirsch, E. C., Rooney, T., Ruberg, M., and Brice, A. (2003). Parkin prevents mitochondrial swelling and cytochrome c release in mitochondria-dependent cell death. Hum. Mol. Genet. 12, 517-526.

Deleidi, M., Hallett, P. J., Koprich, J. B., Chung, C. Y., and Isacson, O. (2010). The Toll-like receptor3 agonist polyinosinic:polycytidylic acid triggers nigrostriatal dopaminergic degeneration. J. Neurosci. 30, 16091-16101.

Di Rosa, G., Puzzo, D., Sant'Angelo, A., Trinchese, F., and Arancio, O. (2003). Alpha-synuclein: between synaptic function and dysfunction. Histol. Histopathol. 18, 1257-1266.

Diebold, S. S., Kaisho, T., Hemmi, H., Akira, S., and Reis E Sousa, C. (2004). Innate antiviral responses by means of TLR7-mediated recognition of single-stranded RNA. Science 303, 1529-1531.

Doss-Pepe, E. W., Chen, L., and Madura, K. (2005). Alpha-synuclein and parkin contribute to the assembly of ubiquitin lysine 63-linked multiubiquitin chains. J. Biol. Chem. 280, 16619-16624.

Dutta, G., Zhang, P., and Liu, B. (2008). The lipopolysaccharide Parkinson's disease animal model: mechanistic studies and drug discovery. Fundam. Clin. Pharmacol. 22, 453-464. 
Eilam, R., Peter, Y., Elson, A., Rotman, G., Shiloh, Y., Groner, Y., and Segal, M. (1998). Selective loss of dopaminergic nigro-striatal neurons in brains of Atm-deficient mice. Proc. Natl. Acad. Sci. U.S.A. 95, 12653-12656.

Espay, A. J., and Henderson, K. K. (2011). Postencephalitic parkinsonism and basal ganglia necrosis due to Epstein-Barr virus infection. Neurology 76, 1529-1530.

Fearnley, J. M., and Lees, A. J. (1991). Ageing and Parkinson's disease: substantia nigra regional selectivity. Brain 114 (Pt 5), 2283-2301.

Ferrer, I. (2009). Early involvement of the cerebral cortex in Parkinson's disease: convergence of multiple metabolic defects. Prog. Neurobiol. 88, 89-103.

Fortin, D. L., Nemani, V. M., Voglmaier, S. M., Anthony, M. D., Ryan, T. A., and Edwards, R. H. (2005). Neural activity controls the synaptic accumulation of alpha-synuclein. J. Neurosci. 25, 10913-10921.

Gandhi, S., Muqit, M. M., Stanyer, L., Healy, D. G., Abou-Sleiman, P. M., Hargreaves, I., Heales, S., Ganguly, M., Parsons, L., Lees, A. J., Latchman, D. S., Holton, J. L., Wood, N. W., and Revesz, T. (2006). PINK1 protein in normal human brain and Parkinson's disease. Brain 129, 1720-1731.

Gardet, A., Benita, Y., Li, C., Sands, B. E., Ballester, I., Stevens, C., Korzenik, J. R., Rioux, J. D., Daly, M. J., Xavier, R. J., and Podolsky, D. K. (2010). LRRK2 is involved in the IFN-gamma response and host response to pathogens. J. Immunol. 185, 5577-5585.

Goldberg, M. S., Pisani, A., Haburcak, M., Vortherms, T. A., Kitada, T., Costa, C., Tong, Y., Martella, G., Tscherter, A., Martins, A., Bernardi, G., Roth, B. L., Pothos, E. N., Calabresi, P., and Shen, J. (2005). Nigrostriatal dopaminergic deficits and hypokinesia caused by inactivation of the familial Parkinsonismlinked gene DJ-1. Neuron 45, 489-496.

Goodridge, H. S., Reyes, C. N., Becker, C. A., Katsumoto, T. R., Ma, J., Wolf, A. J., Bose, N., Chan, A. S., Magee, A. S., Danielson, M. E., Weiss, A., Vasilakos, J. P., and Underhill, D. M. (2011). Activation of the innate immune receptor Dectin-1 upon formation of a 'phagocytic synapse'. Nature 472, 471-475.

Habraken, Y., and Piette, J. (2006). NF-kappaB activation by doublestrand breaks. Biochem. Pharmacol. 72, 1132-1141.
Hacker, H., Mischak, H., Miethke, T., Liptay, S., Schmid, R., Sparwasser, T., Heeg, K., Lipford, G. B., and Wagner, H. (1998). CpG-DNA-specific activation of antigen-presenting cells requires stress kinase activity and is preceded by non-specific endocytosis and endosomal maturation. EMBO J. 17, 6230-6240.

Hadian, K., and Krappmann, D. (2011). Signals from the nucleus: activation of NF-kappaB by cytosolic ATM in the DNA damage response. Sci. Signal. 4, pe2.

Halliday, G. M., and Stevens, C. H. (2011). Glia: initiators and progressors of pathology in Parkinson's disease. Mov. Disord. 26, 6-17.

Hamza, T. H., Zabetian, C. P., Tenesa, A., Laederach, A., Montimurro, J., Yearout, D., Kay, D. M., Doheny, K. F., Paschall, J., Pugh, E., Kusel, V. I., Collura, R., Roberts, J., Griffith, A., Samii, A., Scott, W. K., Nutt, J., Factor, S. A., and Payami, H. (2010). Common genetic variation in the HLA region is associated with late-onset sporadic Parkinson's disease. Nat. Genet. 42, 781-785.

Hegde, M. L., Gupta, V. B., Anitha, M., Harikrishna, T., Shankar, S. K., Muthane, U., Subba Rao, K., and Jagannatha Rao, K. S. (2006). Studies on genomic DNA topology and stability in brain regions of Parkinson's disease. Arch. Biochem. Biophys. 449, 143-156.

Herceg, Z., and Wang, Z. Q. (2001). Functions of poly (ADP-ribose) polymerase (PARP) in DNA repair, genomic integrity and cell death. Mutat. Res. 477, 97-110.

Hill-Burns, E. M., Factor, S. A., Zabetian, C. P., Thomson, G., and Payami, H. (2011). Evidence for more than one Parkinson's disease-associated variant within the HLA region. PLoS ONE 6, e27109. doi:10.1371/journal.pone.0027109

Hinz, M., Stilmann, M., Arslan, S. C., Khanna, K. K., Dittmar, G., and Scheidereit, C. (2010). A cytoplasmic ATM-TRAF6-cIAP1 module links nuclear DNA damage signaling to ubiquitin-mediated NFkappaB activation. Mol. Cell 40, 63-74.

Huang, Y., Song, Y. J., Murphy, K., Holton, J. L., Lashley, T., Revesz, T., Gai, W. P., and Halliday, G. M. (2008). LRRK2 and parkin immunoreactivity in multiple system atrophy inclusions. Acta $\mathrm{Neu}$ ropathol. 116, 639-646.

Huynh, D. P., Scoles, D. R., Nguyen, D., and Pulst, S. M. (2003). The autosomal recessive juvenile Parkinson disease gene product, parkin, interacts with and ubiquitinates synaptotagmin XI. Hum. Mol. Genet. 12, 2587-2597.

Ikeda, F., and Dikic, I. (2008). Atypical ubiquitin chains: new molecular signals. "Protein Modifications: Beyond the Usual Suspects" review series. EMBO Rep. 9, 536-542.

Into, T., Inomata, M., Niida, S. Murakami, Y., and Shibata, K. (2010). Regulation of MyD88 aggregation and the MyD88-dependent signaling pathway by sequestosome 1 and histone deacetylase 6. J. Biol. Chem. 285, 35759-35769.

Iwai, A., Masliah, E., Yoshimoto, M., Ge, N., Flanagan, L., De Silva, H. A., Kittel, A., and Saitoh, T. (1995). The precursor protein of non-A beta component of Alzheimer's disease amyloid is a presynaptic protein of the central nervous system. Neuron 14 467-475.

Kauppinen, T. M., and Swanson, R. A. (2007). The role of poly (ADPribose) polymerase- 1 in CNS disease. Neuroscience 145, 1267-1272.

Kawai, T., and Akira, S. (2006). Innate immune recognition of viral infection. Nat. Immunol. 7, 131-137.

Kubo, M., Kamiya, Y., Nagashima, R., Maekawa, T., Eshima, K., Azuma, S., Ohta, E., and Obata, F. (2010) LRRK2 is expressed in B-2 but not in B-1 B cells, and downregulated by cellular activation. J. Neuroimmunol. 229, 123-128.

Kubo, S. I., Kitami, T., Noda, S., Shimura, H., Uchiyama, Y., Asakawa, S., Minoshima, S., Shimizu, N. Mizuno, Y., and Hattori, N. (2001). Parkin is associated with cellular vesicles. J. Neurochem. 78, 42-54.

Labbe, C., Boucher, G., Foisy, S., Alikashani, A., Nkwimi, H., David, G., Beaudoin, M., Goyette, P., Charron, G., Xavier, R. J., and Rioux, J. D. (2011). Genome-wide expression profiling implicates a MAST3regulated gene set in colonic mucosal inflammation of ulcerative colitis patients. Inflamm. Bowel Dis. doi: 10.1002/ibd.21887. [Epub ahead of print].

Langston, J. W., and Ballard, P. (1984). Parkinsonism induced by 1-methyl-4-phenyl-1,2,3,6tetrahydropyridine (MPTP): implications for treatment and the pathogenesis of Parkinson's disease. Can. J. Neurol. Sci. 11, 160-165.

Leadbetter, E. A., Rifkin, I. R., Hohlbaum, A. M., Beaudette, B. C., Shlomchik, M. J., and Marshak-Rothstein, A. (2002). Chromatin-IgG complexes activate $B$ cells by dual engagement of IgM and Toll-like receptors. Nature 416, 603-607.

Ledesma, M. D., Galvan, C., Hellias, B., Dotti, C., and Jensen, P. H. (2002). Astrocytic but not neuronal increased expression and redistribution of parkin during unfolded protein stress. J. Neurochem. 83, 1431-1440.

Leng, Y., and Chuang, D. M. (2006). Endogenous alpha-synuclein is induced by valproic acid through histone deacetylase inhibition and participates in neuroprotection against glutamate-induced excitotoxicity. J. Neurosci. 26 , 7502-7512.

Lindersson, E., Beedholm, R., Hojrup, P., Moos, T., Gai, W., Hendil, K. B., and Jensen, P. H. (2004). Proteasomal inhibition by alpha-synuclein filaments and oligomers. J. Biol. Chem. 279, 12924-12934.

Ling, Z., Gayle, D. A., Ma, S. Y., Lipton, J. W., Tong, C. W., Hong, J. S., and Carvey, P. M. (2002). In utero bacterial endotoxin exposure causes loss of tyrosine hydroxylase neurons in the postnatal rat midbrain. Mov. Disord. 17, 116-124.

Liu, B. (2006). Modulation of microglial pro-inflammatory and neurotoxic activity for the treatment of Parkinson's disease. AAPS J. 8, E606-E621.

Liu, Y., Fallon, L., Lashuel, H. A., Liu, Z., and Lansbury, P. T. Jr. (2002). The UCH-L1 gene encodes two opposing enzymatic activities that affect alpha-synuclein degradation and Parkinson's disease susceptibility. Cell 111, 209-218.

Mandir, A. S., Przedborski, S., Jackson-Lewis, V., Wang, Z. Q., Simbulan-Rosenthal, C. M., Smulson, M. E., Hoffman, B. E., Guastella, D. B., Dawson, V. L., and Dawson, T. M. (1999). Poly (ADP-ribose) polymerase activation mediates 1-methyl-4-phenyl-1, 2,3,6-tetrahydropyridine (MPTP)induced parkinsonism. Proc. Natl. Acad. Sci. U.S.A. 96, 5774-5779.

McGeer, P. L., Itagaki, S., Boyes, B. E., and McGeer, E. G. (1988). Reactive microglia are positive for HLA-DR in the substantia nigra of Parkinson's and Alzheimer's disease brains. Neurology 38, 1285-1291.

McNaught, K. S., Olanow, C. W., Halliwell, B., Isacson, O., and Jenner, P. (2001). Failure of the ubiquitinproteasome system in Parkinson's disease. Nat. Rev. Neurosci. 2, 589-594.

Miklossy, J., Doudet, D. D., Schwab, C., Yu, S., Mcgeer, E. G., and Mcgeer, P. L. (2006). Role of ICAM-1 in persisting 
inflammation in Parkinson disease and MPTP monkeys. Exp. Neurol. 197, 275-283.

Mirza, B., Hadberg, H., Thomsen, P., and Moos, T. (2000). The absence of reactive astrocytosis is indicative of a unique inflammatory process in Parkinson's disease. Neuroscience 95, 425-432.

Muqit, M. M., Gandhi, S., and Wood, N. W. (2006). Mitochondria in Parkinson disease: back in fashion with a little help from genetics. Arch. Neurol. 63, 649-654.

Nakahira, K., Haspel, J. A., Rathinam, V. A., Lee, S. J., Dolinay, T., Lam, H. C., Englert, J. A., Rabinovitch, M., Cernadas, M., Kim, H. P., Fitzgerald, K. A., Ryter, S. W., and Choi, A. M. (2011). Autophagy proteins regulate innate immune responses by inhibiting the release of mitochondrial DNA mediated by the NALP3 inflammasome. Nat. Immunol. 12, 222-230.

Nguyen, M. D., Julien, J. P., and Rivest, S. (2002). Innate immunity: the missing link in neuroprotection and neurodegeneration? Nat. Rev. Neurosci. 3, 216-227.

Nusinzon, I., and Horvath, C. M. (2003). Interferon-stimulated transcription and innate antiviral immunity require deacetylase activity and histone deacetylase 1. Proc. Natl. Acad. Sci. U.S.A. 100, 14742-14747.

Orr, C. F., Rowe, D. B., and Halliday, G. M. (2002). An inflammatory review of Parkinson's disease. Prog. Neurobiol. 68, 325-340.

Orr, C. F., Rowe, D. B., Mizuno, Y., Mori, H., and Halliday, G. M. (2005). A possible role for humoral immunity in the pathogenesis of Parkinson's disease. Brain 128, 2665-2674.

Outeiro, T. F., Kontopoulos, E., Altmann, S. M., Kufareva, I., Strathearn, K. E., Amore, A. M., Volk, C. B., Maxwell, M. M., Rochet, J. C., Mclean, P. J., Young, A. B., Abagyan, R., Feany, M. B., Hyman, B. T., and Kazantsev, A. G. (2007). Sirtuin 2 inhibitors rescue alphasynuclein-mediated toxicity in models of Parkinson's disease. Science 317, 516-519.

Perry, V. H. (2004). The influence of systemic inflammation on inflammation in the brain: implications for chronic neurodegenerative disease. Brain Behav. Immun. 18, 407-413.

Piccinini, M., Mostert, M., Croce, S., Baldovino, S., Papotti, M., and Rinaudo, M. T. (2003). Interferongamma-inducible subunits are incorporated in human brain $20 \mathrm{~S}$ proteasome. J. Neuroimmunol. 135, 135-140.
Qi, B., Huang, Y., Rowe, D., and Halliday, G. (2007). VISA - a pass to innate immunity. Int. J. Biochem. Cell Biol. 39, 287-291.

Rentzos, M., Nikolaou, C., Andreadou, E., Paraskevas, G. P., Rombos, A., Zoga, M., Tsoutsou, A., Boufidou, F., Kapaki, E., and Vassilopoulos, D. (2009). Circulating interleukin10 and interleukin-12 in Parkinson's disease. Acta Neurol. Scand. 119, 332-337.

Rivett, A. J., Bose, S., Brooks, P., and Broadfoot, K. I. (2001). Regulation of proteasome complexes by gamma-interferon and phosphorylation. Biochimie 83, 363-366.

Savidge, T. C., Sofroniew, M. V., and Neunlist, M. (2007). Starring roles for astroglia in barrier pathologies of gut and brain. Lab. Invest. 87, 731-736.

Schapira, A. H., Cooper, J. M., Dexter, D., Jenner, P., Clark, J. B., and Marsden, C. D. (1989). Mitochondrial complex I deficiency in Parkinson's disease. Lancet 1, 1269.

Schmidt, S., Linnartz, B., Mendritzki, S., Sczepan, T., Lubbert, M., Stichel, C. C., and Lubbert, H. (2011). Genetic mouse models for Parkinson's disease display severe pathology in glial cell mitochondria. Hum. Mol. Genet. 20, 1197-1211.

Scumpia, P. O., Kelly, K. M., Reeves, W. H., and Stevens, B. R. (2005). Double-stranded RNA signals antiviral and inflammatory programs and dysfunctional glutamate transport in TLR3-expressing astrocytes. Glia 52, 153-162.

Seth, R. B., Sun, L., and Chen, Z. J. (2006). Antiviral innate immunity pathways. Cell Res. 16, 141-147.

Seth, R. B., Sun, L., Ea, C. K., and Chen, Z. J. (2005). Identification and characterization of MAVS, a mitochondrial antiviral signaling protein that activates NF-kappaB and IRF 3. Cell 122, 669-682.

Shin, Y., Klucken, J., Patterson, C., Hyman, B. T., and Mclean, P. J. (2005). The co-chaperone carboxyl terminus of Hsp70-interacting protein (CHIP) mediates alphasynuclein degradation decisions between proteasomal and lysosomal pathways. J. Biol. Chem. 280, 23727-23734.

Silverman, N., and Maniatis, T. (2001). NF-kappaB signaling pathways in mammalian and insect innate immunity. Genes Dev. 15, 2321-2342.

Skaug, B., and Chen, Z. J. (2010). Emerging role of ISG15 in antiviral immunity. Cell 143, 187-190.
Song, Y. J., Huang, Y., and Halliday, G. M. (2011). Clinical correlates of similar pathologies in parkinsonian syndromes. Mov. Disord. 26, 499-506.

Stefanova, N., Fellner, L., Reindl, M. Masliah, E., Poewe, W., and Wenning, G. K. (2011). Toll-like receptor 4 promotes alpha-synuclein clearance and survival of nigral dopaminergic neurons. Am. J. Pathol. 179, 954-963.

Steurer, J. (2011). [Nonsteroidal analgesics have a protective effect against Parkinson disease]. Praxis (Bern 1994) 100, 617-618.

Stone, D. K., Reynolds, A. D., Mosley, R. L., and Gendelman, H. E. (2009). Innate and adaptive immunity for the pathobiology of Parkinson's disease. Antioxid. Redox Signal. 11, 2151-2166.

Strauss, K. M., Martins, L. M., PlunFavreau, H., Marx, F. P., Kautzmann S., Berg, D., Gasser, T., Wszolek, Z. Muller, T., Bornemann, A., Wolburg, H., Downward, J., Riess, O., Schulz, J. B., and Kruger, R. (2005). Loss of function mutations in the gene encoding Omi/HtrA2 in Parkinson's disease. Hum. Mol. Genet. 14 2099-2111.

Takahashi-Fujigasaki, J., and Fujigasaki, H. (2006). Histone deacetylase (HDAC) 4 involvement in both Lewy and Marinesco bodies. Neuropathol. Appl. Neurobiol. 32, 562-566.

Tanaka, Y., Engelender, S., Igarashi, S., Rao, R. K., Wanner, T., Tanzi, R. E., Sawa, A., V, L. D., Dawson, T. M., and Ross, C. A. (2001) Inducible expression of mutant alpha-synuclein decreases proteasome activity and increases sensitivity to mitochondria-dependent apoptosis. Hum. Mol. Genet. 10 919-926.

Tang, E. D., and Wang, C. Y. (2010). TRAF5 is a downstream target of MAVS in antiviral innate immune signaling. PLoS ONE 5, e9172. doi:10.1371/journal.pone.0009172

Torkvist, L., Halfvarson, J., Ong, R. T., Lordal, M., Sjoqvist, U., Bresso, F., Bjork, J., Befrits, R., Lofberg, R., Blom, J., Carlson, M., Padyukov, L., D’Amato, M., Seielstad, M., and Pettersson, S. (2010). Analysis of 39 Crohn's disease risk loci in Swedish inflammatory bowel disease patients. Inflamm. Bowel Dis. 16, 907-909.

Umeno, J., Asano, K., Matsushita, T., Matsumoto, T., Kiyohara, Y., Iida, M., Nakamura, Y., Kamatani, N., and Kubo, M. (2011). Meta-analysis of published studies identified eight additional common susceptibility loci for Crohn's disease and ulcerative colitis. Inflamm. Bowel. Dis. 17, 2407-2415.

Valente, E. M., Abou-Sleiman, P. M., Caputo, V., Muqit, M. M., Harvey, K., Gispert, S., Ali, Z., Del Turco, D., Bentivoglio, A. R., Healy, D. G., Albanese, A., Nussbaum, R., Gonzalez-Maldonado, R., Deller, T., Salvi, S., Cortelli, P., Gilks, W. P., Latchman, D. S., Harvey, R. J., Dallapiccola, B., Auburger, G., and Wood, N. W. (2004). Hereditary early-onset Parkinson's disease caused by mutations in PINK1. Science 304, 1158-1160.

Van Limbergen, J., Wilson, D. C., and Satsangi, J. (2009). The genetics of Crohn's disease. Annu. Rev. Genomics Hum. Genet. 10, 89-116.

Villaran, R. F., Espinosa-Oliva, A. M., Sarmiento, M., De Pablos, R. M., Arguelles, S., Delgado-Cortes, M. J., Sobrino, V., Van Rooijen, N., Venero, J. L., Herrera, A. J., Cano, J., and Machado, A. (2010). Ulcerative colitis exacerbates lipopolysaccharideinduced damage to the nigral dopaminergic system: potential risk factor in Parkinson's disease. J. Neurochem. 114, 1687-1700.

Visintin, A., Latz, E., Monks, B. G., Espevik, T., and Golenbock, D. T. (2003). Lysines 128 and 132 enable lipopolysaccharide binding to MD2, leading to Toll-like receptor-4 aggregation and signal transduction. J. Biol. Chem. 278, 48313-48320.

Wahner, A. D., Bronstein, J. M., Bordelon, Y. M., and Ritz, B. (2007). Nonsteroidal anti-inflammatory drugs may protect against Parkinson disease. Neurology 69, 1836-1842.

West, A. B., Moore, D. J., Biskup, S., Bugayenko, A., Smith, W. W., Ross, C. A., Dawson, V. L., and Dawson, T. M. (2005). Parkinson's diseaseassociated mutations in leucine-rich repeat kinase 2 augment kinase activity. Proc. Natl. Acad. Sci. USA 102, 16842-16847.

West, A. P., Koblansky, A. A., and Ghosh, S. (2006). Recognition and signaling by Toll-like receptors. Annu. Rev. Cell Dev. Biol. 22, 409-437.

West, A. P., Shadel, G. S., and Ghosh, S. (2011). Mitochondria in innate immune responses. Nat. Rev. Immunol. 11, 389-402.

Wilms, H., Rosenstiel, P., Sievers, J., Deuschl, G., Zecca, L., and Lucius, R. (2003). Activation of microglia by human neuromelanin is NFkappaB dependent and involves p38 mitogen-activated protein kinase: implications for Parkinson's disease. FASEB J. 17, 500-502. 
Wood, L. M., Sankar, S., Reed, R. E., Haas, A. L., Liu, L. F., Mckinnon, P., and Desai, S. D. (2011). A novel role for ATM in regulating proteasome-mediated protein degradation through suppression of the ISG15 conjugation pathway. PLoS ONE 6, e16422. doi:10.1371/journal.pone. 0016422

Wu, C. J., Conze, D. B., Li, T., Srinivasula, S. M., and Ashwell, J. D. (2006). NEMO is a sensor of Lys 63-linked polyubiquitination and functions in NF-kappaB activation. Nat. Cell Biol. 8, 398-406.
Zhang, Y., Gao, J., Chung, K. K., Huang, H., Dawson, V. L., and Dawson, T. M. (2000). Parkin functions as an E2dependent ubiquitin- protein ligase and promotes the degradation of the synaptic vesicle-associated protein, CDCrel-1. Proc. Natl. Acad. Sci. U.S.A. 97, 13354-13359.

Zhang, L., Shimoji, M., Thomas, B., Moore, D. J., Yu, S. W., Marupudi, N. I., Torp, R., Torgner, I. A., Ottersen, O. P., Dawson, T. M., and Dawson, V. L. (2005). Mitochondrial localization of the Parkinson's disease related protein
DJ-1: implications for pathogenesis. Hum. Mol. Genet. 14, 2063-2073.

Conflict of Interest Statement: The authors declare that the research was conducted in the absence of any commercial or financial relationships that could be construed as a potential conflict of interest.

Received: 16 December 2011; paper pending published: 07 February 2012; accepted: 19 February 2012; published online: 08 March 2012.
Citation: Huang $Y$ and Halliday GM (2012) Aspects of innate immunity and Parkinson's disease. Front. Pharmacol. 3:33. doi: 10.3389/fphar.2012.00033

This article was submitted to Frontiers in Neuropharmacology, a specialty of Frontiers in Pharmacology.

Copyright (c) 2012 Huang and Halliday. This is an open-access article distributed under the terms of the Creative Commons Attribution Non Commercial License, which permits noncommercial use, distribution, and reproduction in other forums, provided the original authors and source are credited. 